\title{
Laser collapse performance in blastocysts applied before vitrification
}

\author{
José Fernando de Macedo1, Maristela Rodrigues Oliveira1*, Luiz Mauro Oliveira Gomes, \\ Gustavo Capinzaiki de Macedo', Giovanna Capinzaiki de Macedo, Daniela Oliveira Gomes', \\ Sandra Irene Sprogis dos Santos ${ }^{2}$ \\ ${ }^{1}$ Reproferty - Centro de Reprodução Humana, São José dos Campos, SP, Brasil \\ Fundação Universitária Vida Cristã (FUNVIC), Faculdade de Pindamonhangaba, Pindamonhangaba, SP, Brasil
}

\section{Abstract}

The objetive of the present study was to investigate the effect of the reduction of blastocele fluid before vitrification with the application of collapsing and the effects of this procedure on the expected results of in vitro fertilization protocols. Methods: A retrospective casecontrol study was conducted with patients who sought assisted fertilization services from January 2015 to October 2017 at Reproferty Clinic. After submission to the ethics committee, data from 106 patients were divided into two groups: 42 cases represented by those who had artificially collapsed blastocysts per laser pulse before vitrification and 64 controls corresponding to patients where artificial shrinkage of expanded blastocysts was not performed. By statistical analysis, the means and standard deviation of each group were obtained, which were compared by the Mann-Whitney test, at a 95\% significance level. Results: the results showed that there was statistical significance comparing the group of cases and controls in the parameters related to embryo freezing, survival and transference as well as to the rates of positive beta human chorionic gonadotropin, clinical pregnancy and live births. Conclusions: the study demonstrated evidence that vitrification after artificial laser collapse of the blastocyst is safe, effective, and more efficient than vitrification of non-collapsed blastocysts in vitro fertilization protocols, however further studies are needed to evaluate the efficiency of artificial shrinkage in routine protocols.

Keywords: blastocyst; laser collapse; vitrification; in vitro fertilization; embryo implantation; artificial shrinkage.

\section{Introduction}

In vitro fertilization (IVF) technologies have brought great hopes for infertile couples in the world. However, the success of embryo implantation and decrease of perinatal morbidity depends not only on its quality, but also on the receptivity of the endometrium as well as the maternal microenvironment and embryonic signaling with the uterine cavity. ${ }^{1,2}$

In IVF centers, more and more specialists have shifted to transference of frozen embryos (TEC), instead of fresh transfer..$^{3-5}$ This is due to the fact that the transfer of fresh embryos in patients with ovarian hyperstimulation syndrome (OHSS) can lead to death risk for the patient. ${ }^{5-7}$

Emphasizing the importance of the TEC, there are many reports that a stimulation in the treatment of IVF and the exposure of women submitted to high hormone levels may alter endometrial receptivity. ${ }^{8}$

Financial support: None.

Conflicts of interest: The authors declare no conflicts of interest.

Submitted: September 12, 2018.

Accepted: March 22, 2019.

The study was carried out at Reproferty - Centro de Reprodução Humana, São José dos Campos, SP, Brasil.

Copyright Macedo et al. This is an Open Access article distributed under the terms of the Creative Commons Attribution License, which permits unrestricted use, distribution, and reproduction in any medium, provided the original work is properly cited. 
Based on these facts, many centers have chosen to freeze all embryos to transfer them in a next cycle, method known as "Freeze-all strategy". $1,5,7,9$

The first pregnancy obtained by transfer of frozen and thawed embryos was reported by Trouson and Mohr in 1983 and since then, the cryopreservation of embryos has been used as standard procedure in human reproduction clinics. ${ }^{10-12}$

Thus, three main methods of cryopreservation have been employed: slow freezing, ultra fast freezing and vitrification.

Cryopreservation of gametes or embryos plays an important role, it is performed to disrupt all biological processes in a cell, decreasing the cell temperature to $-196^{\circ} \mathrm{C}$, where at this temperature, the metabolic activity is discontinued. ${ }^{13}$

However the cell is composed of $80 \%$ water and extreme temperatures can be lethal due to unavoidable frost damage. ${ }^{14}$

Therefore, many studies have been reported showing reduced time of the cryopreservation procedure, aiming to eliminate the high costs with equipment and also to improve the quality of frozen and thawed embryos in order to promote good results in the pregnancy rate..$^{8,11,15}$

One way to achieve these goals was through the use of vitrification techniques, which, other than slow freezing, requires a radical increase in both the concentration of the cryoprotectants and the rate of cooling. ${ }^{16,17}$

Current procedures describe that the exposure of the suspended cells in a small volume of cryoprotectants in high concentration, for a short period of time and placed at low temperature directly on nitrogen liquid at - $196^{\circ} \mathrm{C}$ does not allow the formation of ice crystals. Thus, the cryoprotectants act primarily on the biological membranes of the blastomer, or either in the plasmatic membrane and in the organelles avoiding the formation of crystals during the freezing process. ${ }^{18}$

The high cooling rate used for vitrification with tiny liquid volumes, in turn, allows the reduction of cryoprotectants concentration and therefore an improvement in the effectiveness of the technique is verified. ${ }^{4,10}$

Recent advances in embryo culture systems development of human IVF embryos in blastocysts, is a way to select more viable embryos and more receptive to the uterus. The transfer of blastocysts obtained on this way, has become promissory for increasing pregnancy rates. ${ }^{12}$

On the other hand, the technique of embryo vitrification of blastocysts encounters an important limitation. Blastocysts present an internal cavity (blastocele) composed mainly of water that can therefore form ice crystals when the temperature is reduced and can cause internal cell mass and trophectoderm damage. ${ }^{11}$

It is interesting to note that blastocysts have the advantage of containing numerous small cells and the loss of some of these cells during the freezing and thawing is less detrimental to the embryo development. However, it should be emphasized that the formation of ice crystals is directly proportional to the volume of the blastocele liquid which may affect the blastocyst survival rate. ${ }^{4}$

In order to overcome this problem many researchers presented methods for obtaining collapse of the blastocele prior to vitrification, with purpose of increasing the success of the technique. ${ }^{12,18-21}$

The collapse of blastocysts can be induced by mechanical means such as repeated pipetting with micropipettes of different diameters or by drilling the blastocyst using micro needles of different calibers. ${ }^{19}$

Recently, the directed laser pulse was proposed as an alternative to mechanical collapse, and its use is currently widespread. This technique employs high energy, light and, consequently, heat, to dissolve or disintegrate the pellucida zone, thus allowing the removal of a single blastomer of the embryo. The laser performance correlates with three different properties: power, wavelength and pulse duration, which are the determinants of their effects on the embryo and surrounding environment. ${ }^{22}$

In this context, the present study aimed to investigate the effect of reduction of blastocele fluid prior to vitrification with the application of collapse at the effects of this procedure on the expected survival of embryos; of the positive pregnancy result through serology with positive beta human chorionic gonadotropin (BHCG); clinical pregnancy and live births.

\section{Methodology}

A retrospective case-control study was conducted with patients who sought assisted fertilization services in the period from January 2015 to October 2017 at Reproferty Clinic, after submission to the ethics committee. 


\section{Inclusion criteria}

The medical records of patients who had blastocysts expanded, artificially collapsed and not artificially collapsed; vitrified on day five in IVF cycles and thawed for further transfer.

\section{Sample}

The patients were selected and divided into two groups: the group of the study cases represented by 42 patients who had blastocysts artificially collapsed by laser pulse before vitrification and the control group by 64 women whose expanded blastocysts were not artificially shrunk.

\section{Stimulation protocol}

All patients in the study were treated with GnRH antagonist and ovarian hyperstimulation was considered from the administration of gonadotrophins at doses adjusted according to the clinical response. The human chorionic gonadotropin (hCG) was administered for ovulation firing when the follicles reached values greater than $18 \mathrm{~mm}$ in diameter.

\section{Embryonic culture and artificial laser collapse}

Removal of oocytes was performed 36 hours after hCG administration and the oocytes were inseminated by intracytoplasmic sperm injection (ICSI) and placed in culture medium. Fertilization was accessed 18 to $20 \mathrm{~h}$ after injection. The cleaved embryos were transferred on the third day to culture medium specific for blastocysts. Artificial collapse was performed with the use of the Octax 1.48 uM laser (MTG, Germany), with a single pulse of $300 \mu$ s applied at the junction of the trophectoderm cells, giving rise to an opening in the pellucida zone. The collapse was obtained after eight to 10 minutes.

\section{Vitrification of blastocysts}

The blastocysts were vitrified on day five and classified according to the Gardner scale.

Only blastocysts $A A, A B$ and $B B$ with greater blastocele or equal to half of the embryo volume were included in this study. The vitrification of the collapsed blastocysts was done using the Freeze Kit of vitrification according to with the instructions of the Kit. The palettes used were cryotop.

\section{Desvitrification of blastocysts}

The heating was performed with the thaw vitrification Kit according to with the manufacturer's instructions and the blastocysts were transferred to the culture. Its survival was determined by the presence of internal cell mass and trophectoderm, as well as by the expansion of the blastocele cavity, after three hours from thawing.

\section{Transfer of blastocysts}

After endometrial preparation, the respective surviving blastocysts of each patient were evaluated and transferred to the uterus. Pregnancy was first confirmed by the serology of BhCG with positive result, 12 days after transfer. The clinical pregnancy was determined by the presence of a heart beat on ultrasound examination, 30 days after the transfer.

The number of live births after transfer of collapsed, vitrified and devitrified blastocysts were also computed.

\section{Statistic}

In the statistical analysis, the means and standard deviation of each group, which were compared by the Mann-Whitney test, at a level of $95 \%$ of significance.

\section{Results}

We retrospectively reviewed the medical records of 106 patients and divided them into two groups according to whether their blastocysts were or were not collapsed (case-controls). The results are shown in Table 1 and Figure 1. 
Table 1. Comparison of collapsed and non-collapsed frozen embryos according to parameters analyzed

\begin{tabular}{lrrr}
\multicolumn{1}{c}{ Parameters } & Collapsed & Non-collapsed & p-value* \\
Age & $35.4 \pm 4.5$ & $34.3 \pm 5.0$ & 0.250 \\
Number of frozen blastocysts & $4.1 \pm 2.8$ & $2.7 \pm 2.2$ & $<0.001$ \\
Number of thawed blastocysts & $2.4 \pm 1.1$ & $2.08 \pm 1.6$ & 0.072 \\
Number of surviving blastocysts & $2.2 \pm 1.0$ & $1.5 \pm 1.3$ & $1.5 \pm 1.3$ \\
Number of transferred blastocysts & $2.0 \pm 1.0$ & $0.9 \pm 0.6$ & 0.005 \\
Transference number & $1.1 \pm 0.5$ & 0.007
\end{tabular}

*non-parametric Mann-Whitney test. $p$ - value $<0.05$.

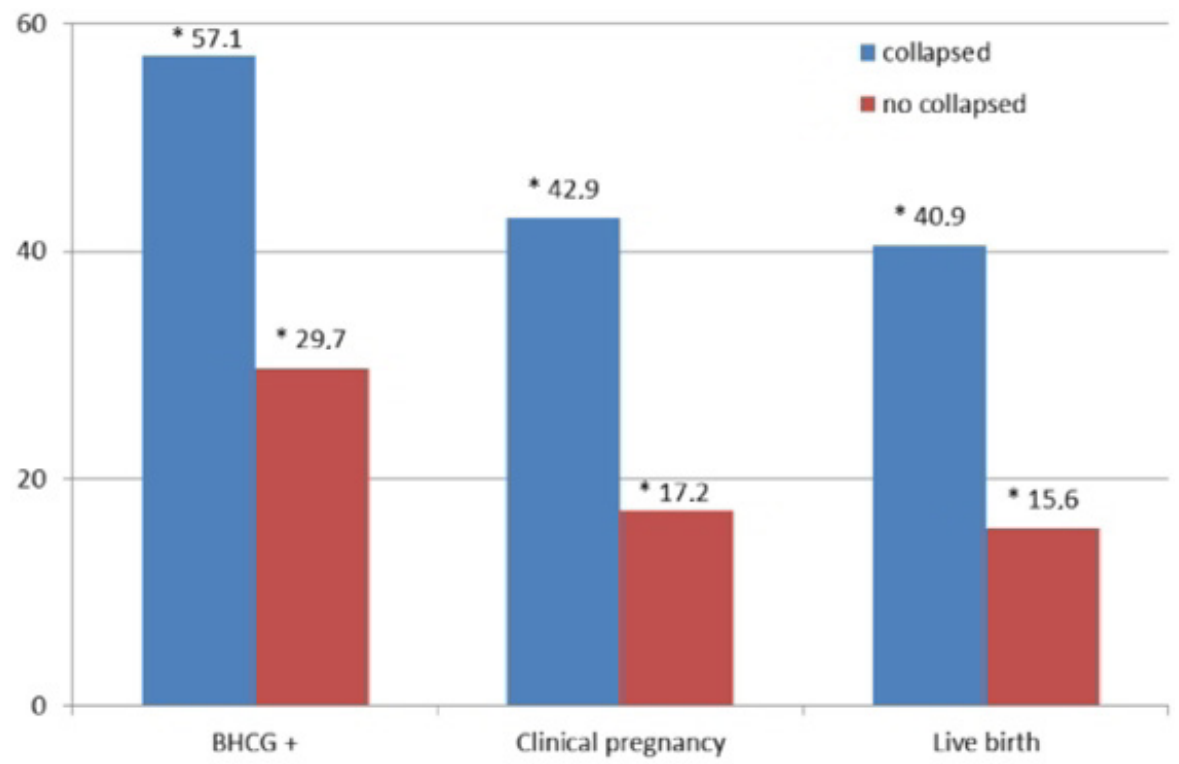

Figure 1. Distribution of the percentages of cases and controls that resulted in BhCG positive, clinical pregnancy and live births for collapsed and non-collapsed embryos. * $p$-value $<0.05$

\section{Discussion}

The different stages of maturation of the blastocyst have an impact on the success of vitrification. Thus, the blastocyst with a small blastocele and non-expanded cavity differs structurally from the expanded blastocyst because the las one contains a large volume of liquid, providing a longer exposure time to the cryoprotectants and a greater risk of formation of ice crystals. ${ }^{23,24}$ In addition, human blastocysts in comparison with those of other mammals such as the rat and cattle, suffer more damage due to the formation of ice, probably because they are less permeable to cryoprotectants and water, shrinking more slowly in cryoprotective solutions than blastocysts of the other animals mentioned. ${ }^{25-27}$

In the present study, it was found that the use of blastocyst collapse with a little laser shot at the junction between two trophectoderm cells, in a region away from the internal cellular mass, before vitrification improved embryo survival, since among the non-collapsed blastocysts all the analyzed rates were lower. This difference can be attributed to inappropriate dehydration and mechanical damage caused by the formation of ice crystals that should be avoided reducing the water content of the blastocele by artificial shrinkage.

In this context, Mukaida et al. ${ }^{19}$ concluded that a large blastocele may decrease the potential of cryopreservation, but the process of shrinkage before vitrification, even if artificial, improves statistically the rates of blastocysts survival, of clinical pregnancy and of live births. Iriarte et al. ${ }^{23}$ revealed that the use of collapse in expanded blastocysts increased the survival rate of embryos and reduced the cancellations of post-thaw embryos. 
However, they did not observe differences in pregnancy rate and implantation rate, but attributed the fact to the small sample size of the study.

Duke et al. ${ }^{28}$ demonstrated that more blastocysts survived when suffered mechanical collapse of blastocele during slow freezing. Son et al. ${ }^{29}$ obtained similar results in cases of blastocyst survival mechanically collapsed and vitrified.

In the present study, it was observed that the use of laser in the collapse of blastocysts resulted in minimal damage to the cell, also a higher survival of the frozen embryos and statistical significance in the rate of pregnancy, clinical pregnancy and births. According to Desai et al., ${ }^{18}$ artificial mechanical or laser shrinkage before vitrification can reduce DNA damage in expanded blastocysts and reexpansion after thawing, however incomplete collapse at the moment of vitrification was reported to be more frequent with the use of the mechanical rather than laser collapse. In relation to reexpansion, the authors cited that the use of the laser significantly decreased the recovery time of the blastocysts compared to those mechanically collapsed. Kovačič et al..$^{30}$ in a prospective observational study, using time lapse described that in blastocyst thawing after artificial collapse, reexpansion is faster than in non-collapsed blastocysts, but did not report correlation with the birth rate.

Several papers whose authors experimented the application of the laser collapse technique in expanded blastocysts demonstrated its efficiency, with improvement in survival rate, pregnancy rate and implantation rate, reducing cancellations of transfers after thawing. ${ }^{12,20,31}$

On the other hand, in the research conducted by Marcos et al., ${ }^{32}$ the authors affirm that the collapse reduced the implantation potential of the transferred blastocysts. They reported that the collapse could act adversely in the implantation, either because it affects the quality of the embryo or by directly reducing its implantation capacity resulting in lower rates of clinical pregnancy. It should be noted that in the present study the number of embryos transferred in the group of collapsed was slightly larger due to better survival rate, however Macer et al..$^{33}$ demonstrated that there was no difference in the rate of BHCG positive and implantation when two blastocysts were transferred instead of one.

Complement Chae et al., ${ }^{34}$ referring in their research to groups of embryos of good quality there was no significant difference in the transfer of a or two blastocysts, since the rate of implantation and pregnancy in progress was equal in two groups. Other authors have shown similar results. ${ }^{35-37}$

\section{Conclusion}

The study demonstrated evidence that vitrification after artificial laser collapse of the blastocyst is safe, effective and more efficient than vitrification of non-collapsed blastocysts with respect to: survival, pregnancy, clinical pregnancy and live birth rates. However, more prospective studies are necessary to evaluate the efficiency of artificial shrinkage in routine protocol of stimulation.

\section{References}

1. Roque M, Valle M, Kostolias A, Sampaio M, Geber S. Freeze-all cycle in reproductive medicine: current perspectives. JBRA Assist Reprod. 2017;21(1):49-53. http://dx.doi.org/10.5935/1518-0557.20170012. PMid:28333033.

2. Evans J, Hannan NJ, Edgell TA, Vollenhoven BJ, Lutjen PJ, Osianlis T, et al. Fresh versus frozen embryo transfer: backing clinical decisions with scientific and clinical evidence. Hum Reprod Update. 2014;20(6):808-21. http://dx.doi.org/10.1093/humupd/ dmu027. PMid:24916455.

3. Liebermann J, Pelts EJ, Matthews JM, Sanchez SR, Rapisarda J, Lederer K. Does artificial collpase of human day 6 blastocysts prior to the cooling steps of vitrification improve their probability of increased outcome? Fertil Steril. 2012;98(Suppl 3):S127. http:// dx.doi.org/10.1016/j.fertnstert.2012.07.469.

4. Al-Azawi T, Tavukcuoglu S, Khaki AA, Al-Hasani S. Cryopreservation of human oocytes, zygotes, embryos and blastocysts: a comparison study between slow freezing and ultra rapid (vitrification) methods. Middle East Fertil Soc J. 2013;18(4):223-32. http://dx.doi.org/10.1016/j.mefs.2012.10.008.

5. Ortega-Hrepich C, Stoop D, Guzmán L, Van Landuyt L, Tournaye H, Smitz J, et al. A "freeze-all" embryo strategy after in vitro maturation: a novel approach in women with polycystic ovary syndrome? Fertil Steril. 2013;100(4):1002-7. http://dx.doi.org/10.1016/j. fertnstert.2013.06.018. PMid:23850301.

6. Cota AMM, Lages EL, Mendonça HC, Silva ALM, Amaral MCMS, Caetano JPJ. Avaliação dos resultados de vitrificação de blastocistos. JBRA Assist Reprod. 2011;15(4):27-30.

7. Blockeel C, Drakopoulos P, Santos-Ribeiro S, Polyzos NP, Tournaye H. A fresh look at the freeze-all protocol: a SWOT analysis. Hum Reprod. 2016;31(3):491-7. http://dx.doi.org/10.1093/humrep/dev339. PMid:26724793.

8. Dieamant FC, Petersen CG, Mauri AL, Comar V, Mattila M, Vagnini LD, et al. Fresh embryos versus freeze-all embryos - transfer strategies: nuances of a meta-analysis. JBRA Assist Reprod. 2017;21(3):260-72. http://dx.doi.org/10.5935/1518-0557.20170048. PMid:28837037. 
9. Roque M, Valle M, Guimarães F, Sampaio M, Geber S. Freeze-all policy: fresh vs. frozen-thawed embryo transfer. Fertil Steril. 2015;103(5):1190-3. http://dx.doi.org/10.1016/j.fertnstert.2015.01.045. PMid:25747130.

10. Elnahas A, Alcolak E, Marar EA, Elnahas T, Elnahas K, Palapelas V, et al. Vitrification of human oocytes and different development stages of embryos: an overview. Middle East Fertil Soc J. 2010;15(1):2-9. http://dx.doi.org/10.1016/j.mefs.2010.03.013.

11. Rezazadeh Valojerdi M, Eftekhari-Yazdi P, Karimian L, Hassani F, Movaghar B. Vitrification versus slow freezing gives excellent survival, post warming embryo morphology and pregnancy outcomes for human cleaved embryos. J Assist Reprod Genet. 2009;26(6):347-54. http://dx.doi.org/10.1007/s10815-009-9318-6. PMid:19513822.

12. Darwish E, Magdi Y. Artificial shrinkage of blastocoel using a laser pulse prior to vitrification improves clinical outcome. J Assist Reprod Genet. 2016;33(4):467-71. http://dx.doi.org/10.1007/s10815-016-0662-z. PMid:26843389.

13. Liebermann J. (2012). Vitrification of oocytes and embryos. In: Katkov I, editor. Current frontiers in cryobiology. Rijeka: InTech. p. 169-184. http://dx.doi.org/10.5772/35136.

14. Shetye-Kapdi S, Kagalwale S, Ghandi GN, Pangerkar P. Slow-rate freezing versus vitrification for oocytes and embryos: an evaluation In: Allahbadia GN, Chawla MM, Das RB, Garcia EV, Gandhi G, Merchant R, editors. The Art \& Science of Assisted Reproductive Techniques (ART). London: Taylor \& Francis; 2004. p. 605.

15. Liebermann J, Tucker MJ. Effect of carrier system on the yield of human oocytes and embryos as assessed by survival and developmental potential after vitrification. Reproduction. 2002;124(4):483-9. http://dx.doi.org/10.1530/rep.0.1240483 PMid:12361466.

16. Liebermann J, Tucker MJ. Comparison of vitrification and conventional cryopreservation of day 5 and day 6 blastocysts during clinical application. Fertil Steril. 2006;86(1):20-6. http://dx.doi.org/10.1016/j.fertnstert.2006.01.029. PMid:16762345.

17. Stachecki JJ, Willadsen SM, Wiemer K, Garrisi J, Cohen J. S3 vitrification: a safe, simple, and successful method for blastocyst vitrification. Fertil Steril. 2007;88:S347-8. http://dx.doi.org/10.1016/j.fertnstert.2007.07.1169.

18. Desai N, Szeptycki J, Scott M, AbdelHafez FF, Goldfarb J. Artificial collapse of blastocysts before vitrification: mechanical vs. laser technique and effect on survival, cell number, and cell death in early and expanded blastocysts. Cell Preserv Technol. 2008;6(3):181-90. http://dx.doi.org/10.1089/cpt.2008.0007.

19. Mukaida T, Oka C, Goto T, Takahashi K. Artificial shrinkage of blastocoeles using either a micro-needle or a laser pulse prior to the cooling steps of vitrification improves survival rate and pregnancy outcome of vitrified human blastocysts. Hum Reprod. 2006;21(12):3246-52. http://dx.doi.org/10.1093/humrep/del285. PMid:16936299.

20. Fischer E, Givens C, Conaghan J. Optimization of blastocyst vitrification may require artificial colapse. Fertil Steril. 2011;95(4):S5-6. http://dx.doi.org/10.1016/j.fertnstert.2011.01.047.

21. Bodri D, Sugimoto T, Yao Serna J, Kawachiya S, Kato R, Matsumoto T. Blastocyst collapse is not an independent predictor of reduced live birth: a time-lapse study. Fertil Steril. 2016;105(6):1476-83. http://dx.doi.org/10.1016/j.fertnstert.2016.02.014. PMid:26940789.

22. Taylor TH, Gilchrist JW, Hallowell SV, Hanshew KK, Orris JJ, Glassner MJ, et al. The effects of different laser pulse lengths on the embryo biopsy procedure and embryo development to the blastocyst stage. J Assist Reprod Genet. 2010;27(11):663-7. http:// dx.doi.org/10.1007/s10815-010-9461-0. PMid:20686919.

23. Iriarte YF, Morrilo MJL, Lizana EO, Laso A. Artificial collapse of human blastocysts, before vitrification, improves survival and pregnancy rates. Reprod Biomed Online. 2012;24(Suppl 1):S9. http://dx.doi.org/10.1016/S1472-6483(12)60144-8.

24. Kazemi P, Dashtizad M, Shamsara M, Mahdavinezhad F, Hashemi E, Fayazi S, et al. Effect of blastocoel fluid reduction before vitrification on gene expression in mouse blastocysts. Mol Reprod Dev. 2016;83(8):735-42. http://dx.doi.org/10.1002/mrd.22681. PMid:27409768.

25. Kader AA, Choi A, Orief $Y$, Agarwal A. Factors affecting the outcome of human blastocyst vitrification. Reprod Biol Endocrinol. 2009;7(1):99. http://dx.doi.org/10.1186/1477-7827-7-99. PMid:19758458.

26. Vanderzwalmen P, Connan D, Grobet L, Wirleitner B, Remy B, Vanderzwalmen S, et al. Lower intracellular concentration of cryoprotectants after vitrification than after slow freezing despite exposure to higher concentration of cryoprotectant solutions. Hum Reprod. 2013;28(8):2101-10. http://dx.doi.org/10.1093/humrep/det107. PMid:23592220.

27. Mukaida T, Nakamura S, Tomiyama T, Wada S, Oka C, Kasai M, et al. Vitrification of human blastocysts using cryoloops: clinical outcome of 223 cycles. Hum Reprod. 2003;18(2):384-91. http://dx.doi.org/10.1093/humrep/deg047. PMid:12571178.

28. Duke M, Basile N, Johnson M, Copperman A, Sandler B, Barritt J. Hatched blastocysts that collapse during slow freezing have a higher post-thaw survival rate. Fertil Steril. 2004;82(Suppl 2):S150-1. http://dx.doi.org/10.1016/j.fertnstert.2004.07.383.

29. Son W-Y, Yoon S-H, Yoon H-J, Lee S-M, Lim J-H. Pregnancy outcome following transfer of human blastocysts vitrißed on electron microscopy grids after induced collapse of the blastocoele. Hum Reprod. 2003;18(1):137-9. http://dx.doi.org/10.1093/humrep/ deg029. PMid:12525454.

30. Kovačič B, Taborin M, Vlaisavljević V. Artificial blastocoel collapse of human blastocysts before vitrification and its effect on re-expansion after warming - a prospective observational study using time-lapse microscopy. Reprod Biomed Online. 2018;36(2):121-9. http://dx.doi.org/10.1016/j.rbmo.2017.10.111. PMid:29212605.

31. Fields RA, Werland HJ, Nguyen J, Sieren KR, Turner TG, Silverberg KM. Laser collapsing of blastocysts prior to vitrification leads to better embryonic survival and improved overall IVF cycle outcome. Fertil Steril. 2013;100(3):S106. http://dx.doi.org/10.1016/j. fertnstert.2013.07.1680. 
32. Marcos J, Pérez-Albalá S, Mifsud A, Molla M, Landeras J, Meseguer M. Collapse of blastocysts is strongly related to lower implantation success: a time-lapse study. Hum Reprod. 2015;30(11):2501-8. http://dx.doi.org/10.1093/humrep/dev216. PMid:26355116.

33. Macer ML, Barritt J, Surrey MW, Danzer H, Ghadir S, Chang W, et al. Pregnancy outcomes following single versus double euploid embryo transfer. Fertil Steril. 2017;107(3):e28-9. http://dx.doi.org/10.1016/j.fertnstert.2017.02.051.

34. Chae SJ, Hur CY, Lee WD, Lim JH. Single embryo transfer versus double embryo transfer in vitrified frozen-thawed blastocyst transfer cycles: retrospective analysis of 967 cryopreserved cycles with no more than two blastocysts. Fertil Steril. 2008;90(Suppl 1):S366. https://doi.org/10.1016/j.fertnstert.2008.07.1600.

35. Gremeau AS, Brugnon F, Bouraoui Z, Peikhrishvili R, Janny L, Pouly JL. Outcome of elective single or double embryo transfer in first and second IVF/ICSI cycles. Gynecol Obstet Fertil. 2011;39(2):70-5. http://dx.doi.org/10.1016/j.gyobfe.2010.08.005. PMid:21316284.

36. Kosmas I, Van der Elst J, Devroey P, Tournaye H. Elective single embryo transfer. BJOG. 2008;10:163-70.

37. Forman EJ, Hong KH, Ferry KM, Tao X, Taylor D, Levy B, et al. In vitro fertilization with single euploid blastocyst transfer: a randomized controlled trial. Fertil Steril. 2013;100(1):100-7. http://dx.doi.org/10.1016/j.fertnstert.2013.02.056. PMid:23548942.

\section{*Correspondence}

Maristela Rodrigues Oliveira

R. Santo Agostinho, 179, Vila Adyanna

CEP 12243-800, São José dos Campos, SP, Brasil

Tel.: +55 (12) 3941-5199

E-mail: maristelar1oliveira@gmail.com

\section{Authors information}

JFM - MSc in Biomedical engineering, Physician at Reproferty Human reproduction, gynecology and obstetrics clinic; MRO Specialist in Clinical Analyzes and Senior Embryologist at Reproferty Human reproduction, gynecology and obstetrics clinic; LMOG- Master in Maternal and Child Health and Embryologist at Reproferty Human reproduction, gynecology and obstetrics clinic; GCM and GCM - Medical students and interns at Reproferty Human reproduction, gynecology and obstetrics clinic; DOG - Specialist in Obstetrics and Gynecology, Physician in Reproferty Human reproduction, gynecology and obstetrics clinic; SISS - PhD and professor at Christian Life Fundation-FUNVIC Pharmacy course. 